Thorax (1960), 15, 22.

\title{
HAZARD OF ANTIFOAM EMBOLI FROM A BUBBLE OXYGENATOR
}

\author{
BY \\ A. B. CASSIE, A. G. RIDDELL, AND P. O. YATES \\ From the Departments of Surgery and Pathology, University of Manchester
}

(RECEIVED FOR PUBLICATION OCTOBER 19, 1959)

One of the most popular types of heartlung machine has been the bubble oxygenator introduced by Clark, Gollan, and Gupta (1950) and this has been used successfully in the treatment of many hundreds of patients (Lillehei, Warden, DeWall, Stanley, and Varco, 1957 ; Cooley, Belmonte, De Bakey, and Latson, 1957). However, some workers have experienced difficulty in using this apparatus, particularly on experimental animals. Focal lesions in the brains of dogs that had a partial perfusion with a bubble oxygenator were first described by Giannelli, Molthan, Best, Dull, and Kirby (1957). Similar changes in the brain of both dog and man during total by-pass were described by Taylor and Cavanagh (1958). These foci had the pattern of embolic lesions, but the nature of the emboli was not determined. In a preliminary report from this laboratory (Yates, Cassie, Dark, Jack, and Riddell, 1959), the emboli were identified as being particles of the defoamant, polymethylsiloxane (antifoam A). It is the purpose of this article to review the problem in more detail and present our experimental findings. Similar results have recently been reported by Reed and Kittle (1959).

\section{EXPERIMENTAL MethodS}

In our earlier experiments, using the bubble type oxygenator described by DeWall, Warden, Varco, and Lillehei (1957), it was noted that, if a film of antifoam was applied to the debubbling chamber with a gauze swab, gross particles of antifoam appeared in the saline which was used to check the flow rate before starting perfusion. It became clear that any excess of antifoam was harmful and a method was devised to allow the minimum of antifoam to be used. The apparatus used for these experiments is shown in Fig. 1. The antifoam was made up as a solution in ether $(1: 5)$ and sprayed on to a nylon mesh. This reduced to a minimum the amount of antifoam to be exposed over a large surface area and gave maximum contact between the antifoam and the blood foam. The perfusion rate varied between 40 and $95 \mathrm{ml} . / \mathrm{kg}$, and the oxygen flow rate varied between three and five times the blood rate. The length of the perfusion was usually 30 minutes.

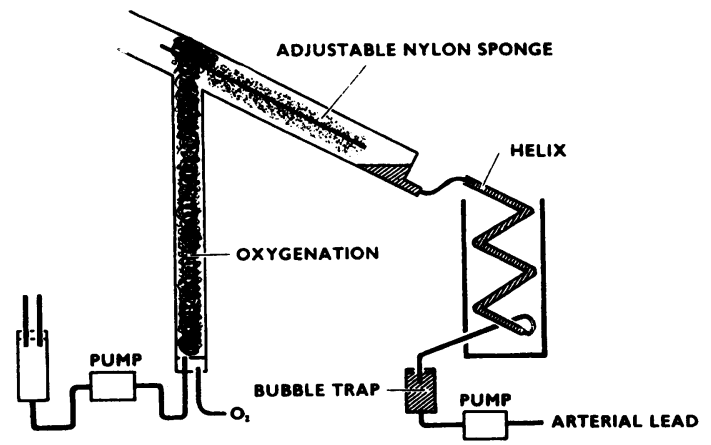

FIG. 1.-Diagram of pump-oxygenator used in these experiments.

All dogs were necropsied after death. Survivors were killed between one and six weeks after perfusion. We counted as survivors only dogs which had lived for at least seven days and were healthy at the time of sacrifice. Tissues taken from the dogs were fixed in $10 \%$ formol saline. Apart from the brains, which were removed whole, blocks were taken for histological examination from other organs, including kidneys, liver, spleen, heart, and lungs. From some $\bigcirc$ of the tissues frozen sections were cut and mounted after staining in a watery medium. For the most part blocks were dehydrated in ethyl alcohol, cleared in xylene, and embedded in paraffin wax. Stained or sections were dehydrated and cleared in the same $N$ solvents before mounting in synthetic resins.

\section{RESUlts}

The results of the experiments are shown in the Table. The mortality throughout the series has $\bar{D}$ been high $(74 \%)$. A number of the deaths can $\stackrel{?}{?}$ be attributed to technical problems related to $?$ developing new procedures; however, $24 \%$ of the $\frac{0}{\mathbb{P}}$ deaths were thought to be cerebral in origin. In $\stackrel{\mathbb{P}}{9}$ the survivors living for seven days or more, no $\stackrel{\mathbb{Q}}{\varrho}$ functional evidence of a neurological disorder was found. 
TABLE

RESULTS OF EXPERIMENTS IN 50 DOGS

\begin{tabular}{|c|c|c|c|c|c|c|c|}
\hline $\begin{array}{l}\text { No. } \\
\text { of } \\
\text { Dog }\end{array}$ & $\begin{array}{c}\text { Flow Rate } \\
\text { (ml./kg. body } \\
\text { weight } / \mathrm{min} .)\end{array}$ & $\begin{array}{c}\text { Time } \\
\text { (min.) }\end{array}$ & Survival & Death & Cause & Pathology & Special Features \\
\hline
\end{tabular}

Antifoam, Applied as Smear, Autoclaved on Defoaming Chamber and Sponge

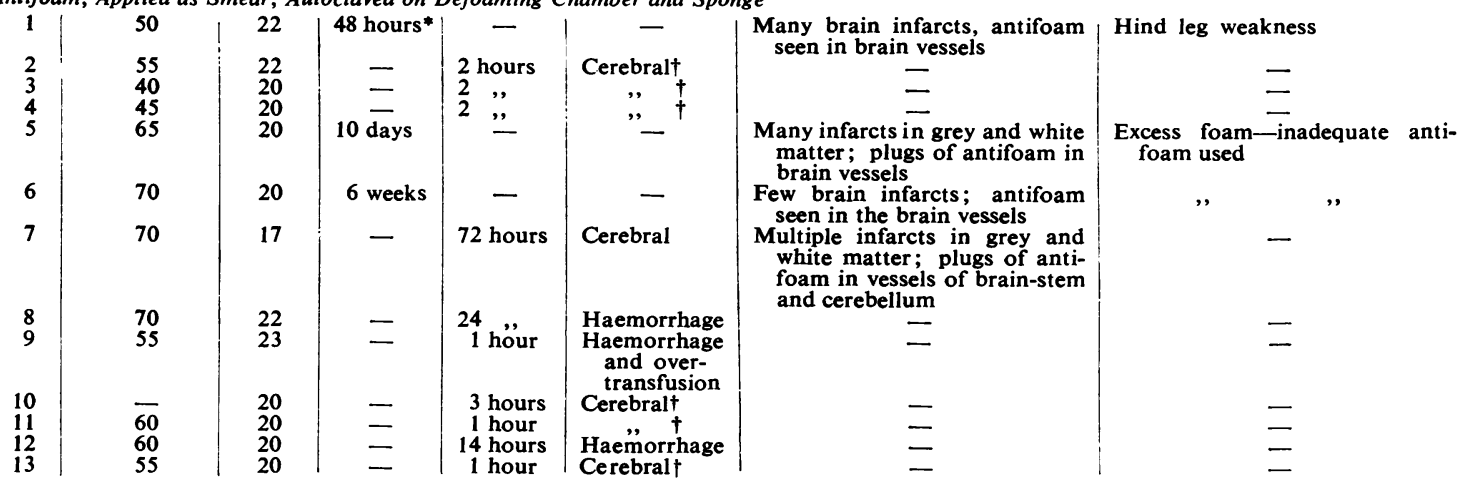

Antifoam on Chamber and Sponge, Autoclaved on, Applied 20\% Solution in Ether as Spray

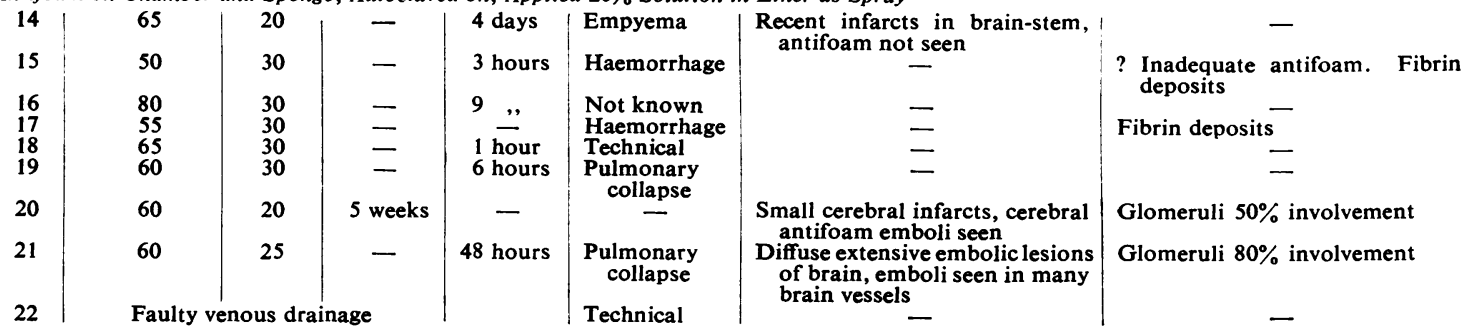

Nylon Sponge Only, Antifoam 20\% in Ether Applied as Spray at Time of Perfusion

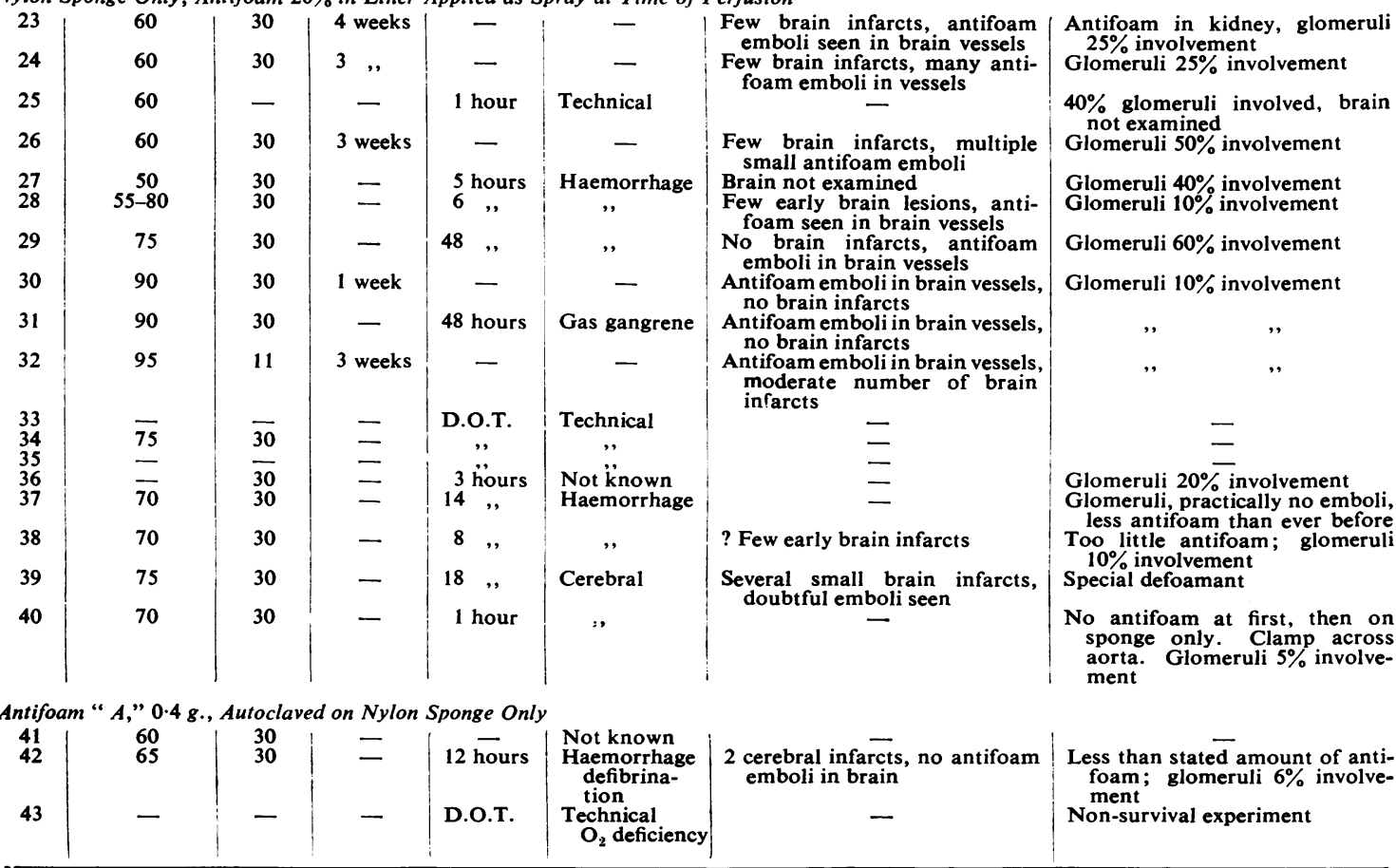


TABLE-continued

\begin{tabular}{|c|c|c|c|c|c|c|c|}
\hline $\begin{array}{c}\text { No. } \\
\text { of } \\
\text { Dog }\end{array}$ & $\begin{array}{c}\text { Flow Rate } \\
\text { (ml./kg. body } \\
\text { weight } / \text { min.) }\end{array}$ & $\begin{array}{l}\text { Time } \\
\text { (min.) }\end{array}$ & Survival & Death & Cause & Pathology & Special Features \\
\hline \multicolumn{8}{|c|}{ Reduced Oxygen Flows } \\
\hline 44 & 65 & 30 & 3 weeks & - & - & No brain infarcts, few antifoam & Glomeruli $30 \%$ involvement \\
\hline 45 & 60 & 30 & 10 days & - & - & $\begin{array}{l}\text { Few small brain infarcts, sparse } \\
\text { brain antifoam emboli }\end{array}$ & $\begin{array}{l}\text { Weakness hind legs; glomerul } \\
25 \% \text { involvement }\end{array}$ \\
\hline 46 & 60 & 30 & - & D.O.T. & Technical & $\begin{array}{l}\text { Brain-no infarcts, antifoam } \\
\text { emboli in vessels }\end{array}$ & $\begin{array}{l}\text { Non-survival experiment; } \\
\text { glomeruli } 12 \% \text { involvement }\end{array}$ \\
\hline $\begin{array}{l}47 \\
48\end{array}$ & $\begin{array}{l}60 \\
60\end{array}$ & $\begin{array}{l}30 \\
30\end{array}$ & 4 weeks & 48 hours & Empyema & $\begin{array}{l}\text { Brain-no infarcts, no emboli } \\
\text { Brain infarcts seen, no antifoam } \\
\text { emboli }\end{array}$ & $\begin{array}{l}\text { Glomeruli } 1 \% \text { involvement } \\
\text { Glomeruli } 15 \% \text { involvement }\end{array}$ \\
\hline 49 & 65 & 30 & 一 & 36 hours & Pulmonary & Brain - small infarcts, no emboli & Glomeruli $6 \%$ involvement \\
\hline 50 &,$^{60}$ & 30 & 10 days & - & Corlip & $\begin{array}{l}\text { Brain-small infarcts; antifoam } \\
\text { present }\end{array}$ & Glomeruli $5 \%$ involvement \\
\hline
\end{tabular}

* First survivor sacrificed at $\mathbf{4 3}$ hours. Included as a survivor because completely normal functionally at time of sacrifice.

+ Brains of early post-operative deaths not submitted for histology in earlier experiments. Mode of death of cerebral type.

Histological examination of the tissues revealed the presence of emboli in all the dogs, irrespective of whether they died immediately after the perfusion or whether they survived and were sacrificed later. The emboli were commonly 15-20 $\mu$ in diameter with occasional ones of $80 \mu$. Often they were elongated and moulded to the cylindrical form of the blood vessels. The material had the negative staining properties of antifoam. It is somewhat refractile but can be seen more clearly with phase-contrast microscopy. The emboli were most easily discovered in the tufts of the renal glomeruli and they could be found here in all animals (Figs. 2 and 3). Since much of the renal capillary bed is conveniently grouped and the glomeruli receive a large fraction of the total blood flow, it was possible by counting the percentage of glomeruli involved to reach a numerical assessment of the number of emboli. In the worst dogs $80 \%$ of glomeruli contained emboli, and over half the capillary tufts in each glomerulus were blocked; in the least affected dogs about $1 \%$ of the glomeruli contained emboli.

Emboli of antifoam were found in 20 of the 25 brains examined. When they were small (15-20 $\mu)$ they were not always related to infarcts. Where they were numerous, they blocked many arterioles and infarcts were produced (Figs. 4 and 5). Larger emboli, whether in grey or white matter, were always near infarcts. These infarcts varied from a perivascular paling of myelin in dogs dying before 48 hours to complete necrosis of tissue in dogs surviving longer (Figs. 6 and 7). At three weeks there was a considerable phagocytic activity by microglia and a surrounding astrocytic gliosis. These lesions varied in size up to about $3 \mathrm{~mm}$. across. Although the vessels containing antifoam emboli showed swelling of the endothelial cells, perhaps the effect of cessation of blood flow, there was no cellular reaction due directly to the antifoam.

In many cases initial sections of cerebral infarcts displayed no obvious embolic cause, but serial sections often revealed the appropriate vessels blocked by antifoam.

The distribution of the infarcts is in agreement with the pattern to be expected from small emboli. Swank and Hain (1952) have shown that small particles of paraffin wax $(15 \mu)$ were distributed in proportion to the density of the capillary bed and were most common in the grey matter. It follows that because of this greater capillary density in the grey matter emboli in this situation are less likely to cause infarcts than in the white matter. Their observations were confirmed by our material. It was found that infarcts and emboli were relatively more common in cerebellum, brainstem, and occipital lobes rather than in frontal regions.

Apart from the kidneys and brain, emboli were rarely found in other organs such as spleen and liver. They were only found after considerable search and are presumably not significant.

Emboli of other substances were found. One dog had fibrin thrombi in considerable quantities. N In several there were platelet thrombi, but these were never numerous. We found no evidence of $N$ oxygen emboli. Gas emboli do not appear to have $\omega$ been a major factor since we account for most of $\bar{F}$ the infarcts by the presence of antifoam emboli.

There was no evidence in any of the dogs of generalized anoxic or ischaemic damage. The $\stackrel{?}{+}$ Purkinje cells of the cerebellum rapidly dis- $\frac{T}{0}$ appeared from other dogs where general ischaemia $\frac{\vec{D}}{\mathbb{D}}$ was deliberately produced by cardiac arrest. In $\stackrel{\odot}{\odot}$ the animals whose circulation was maintained on $\stackrel{\unrhd}{\varrho}$ the heart-lung machine these cells showed no abnormalities outside infarcted regions. 


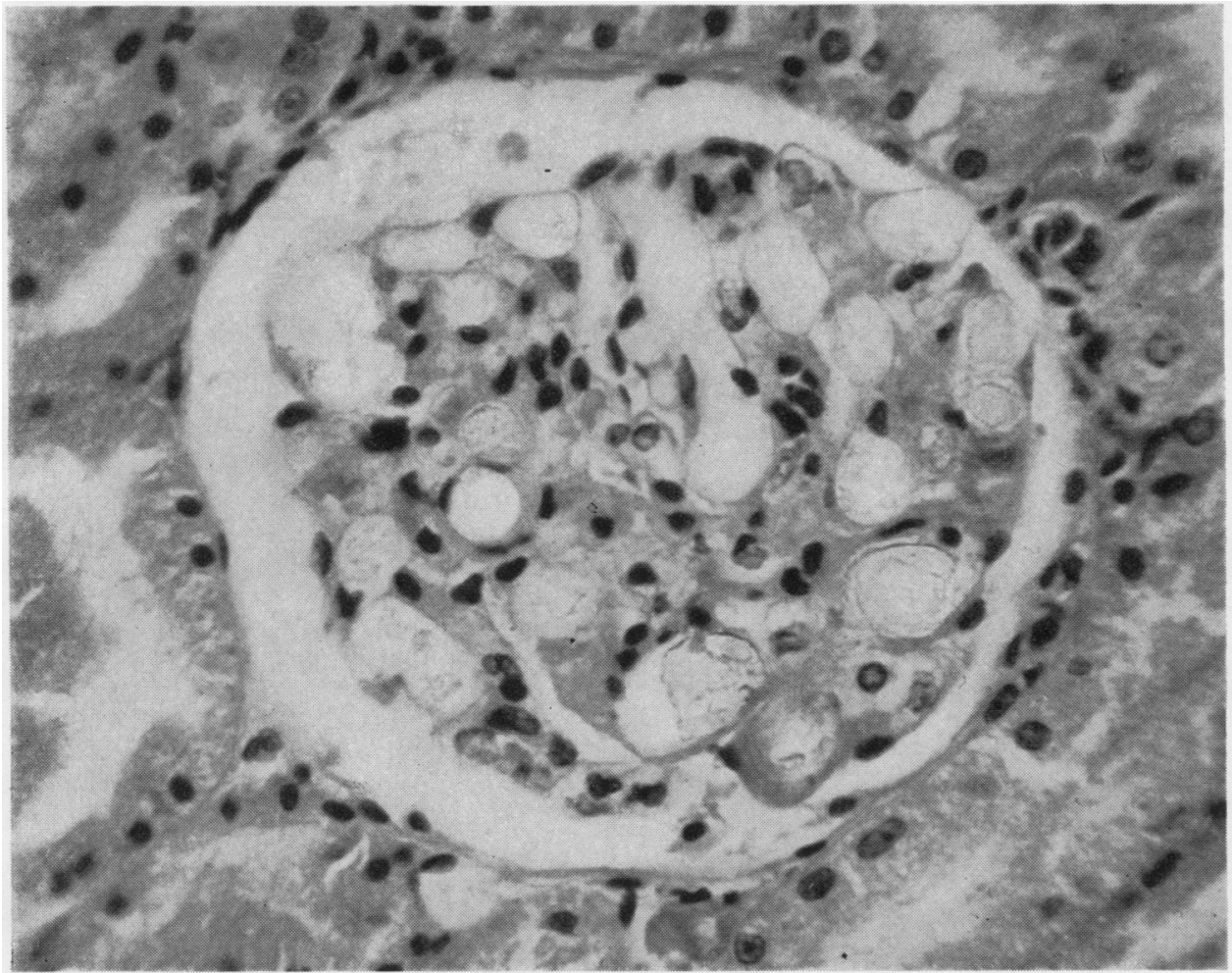

Fig. 2.-Glomerulus from dog No. 21 showing many capillaries distended with antifoam emboli. The granularity of the material is probably due to precipitated silica. Paraffin sections. $\times \mathbf{5 8 0}$.

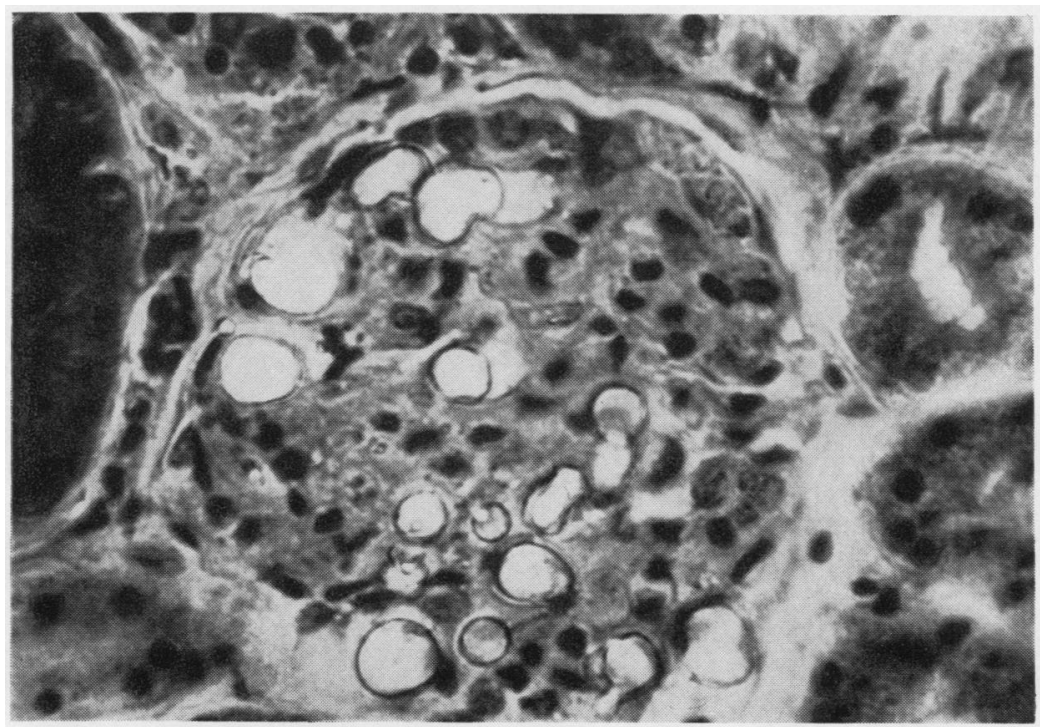

Fig. 3.-Frozen section of kidney from the same animal as in Fig. 2 to show rather refractile appearance of antifoam emboli in glo merular capillaries when no solvents have been applied. $\times 580$. 


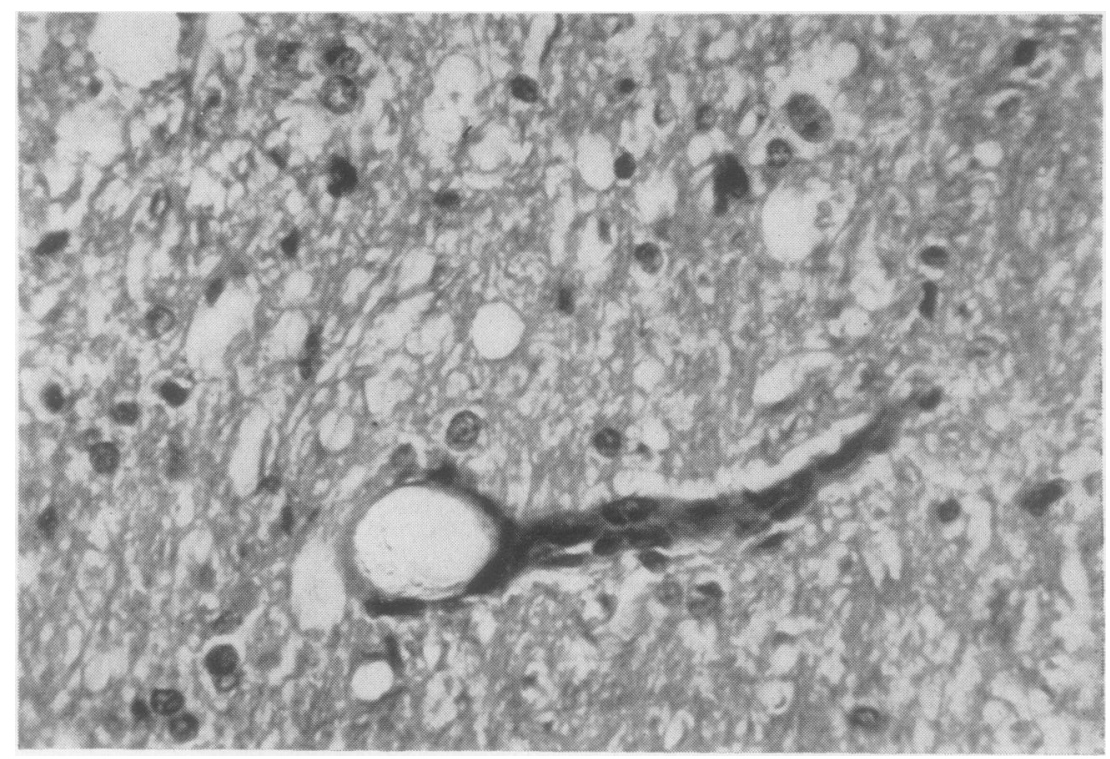

Fig. 14.-Small vessel distended by an antifoam embolus in cerebral white matter from dog No. 5 10 days after perfusion. The endothelium is swollen, but there is no obvious reaction to the embolus. $\times 825$.

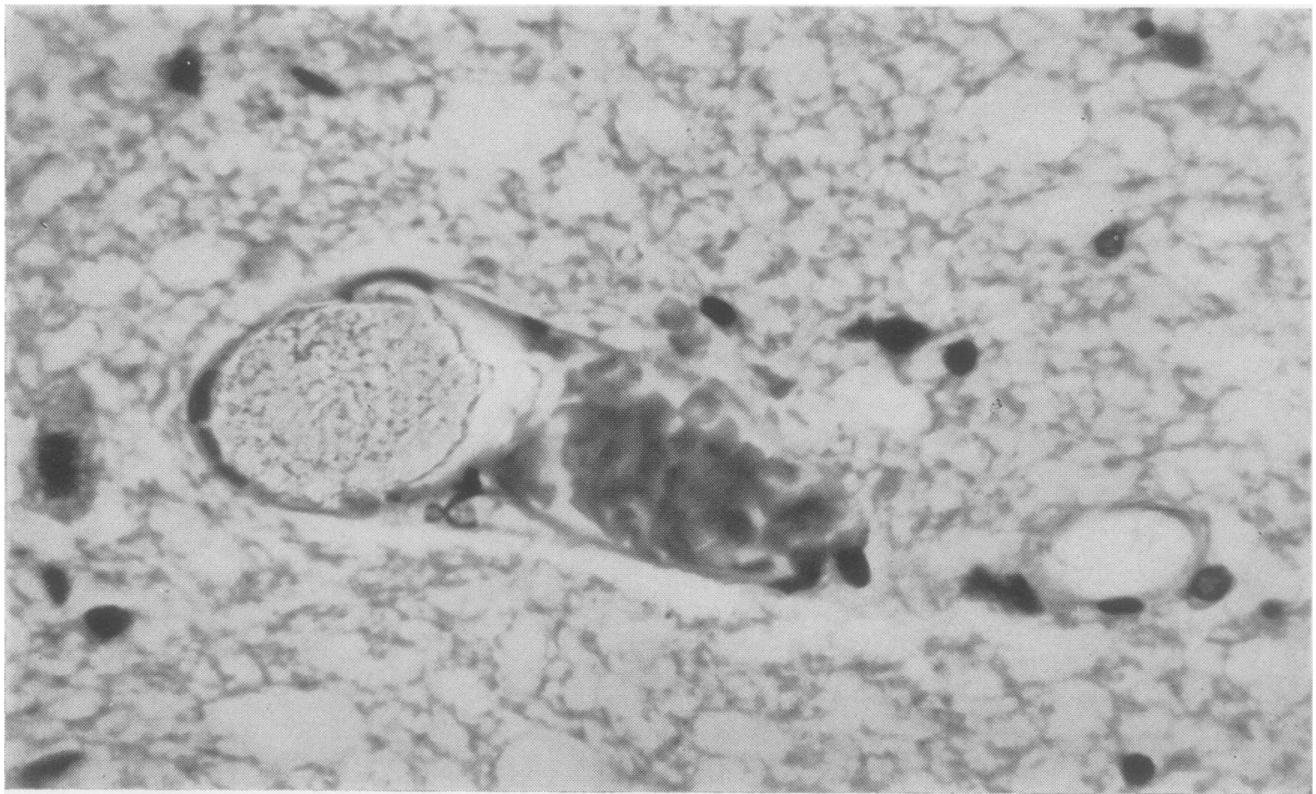

FIG. 5.-Embolus of antifoam plugging a small vessel in an area of early cerebral infarction. Several other vessels in the same area were similarly blocked. Dog No. $21 . \quad \times 825$. 


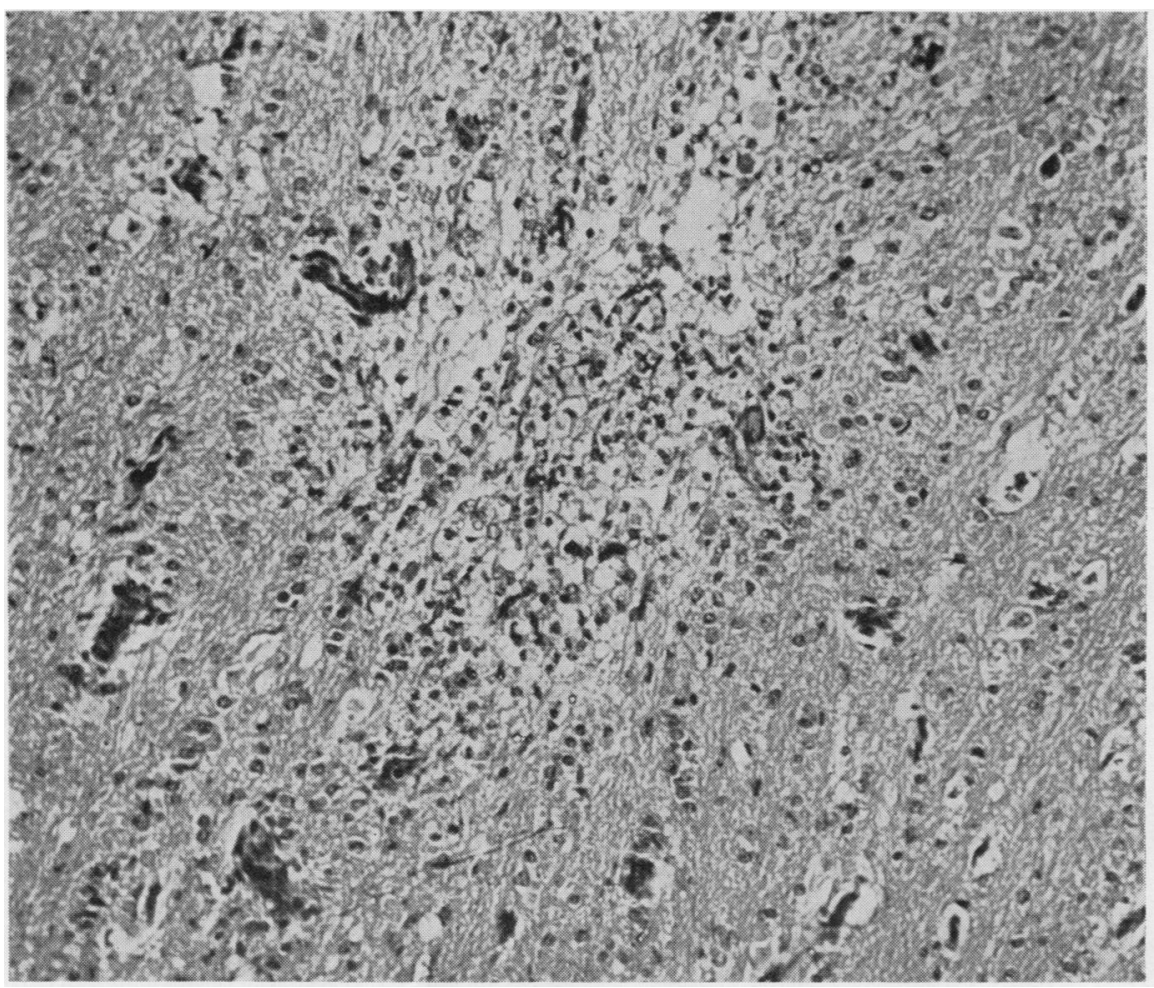

FIG. 6.-Area of infarction of cerebral white matter showing phagocytic invasion. Dog No. 5. $\times 205$.

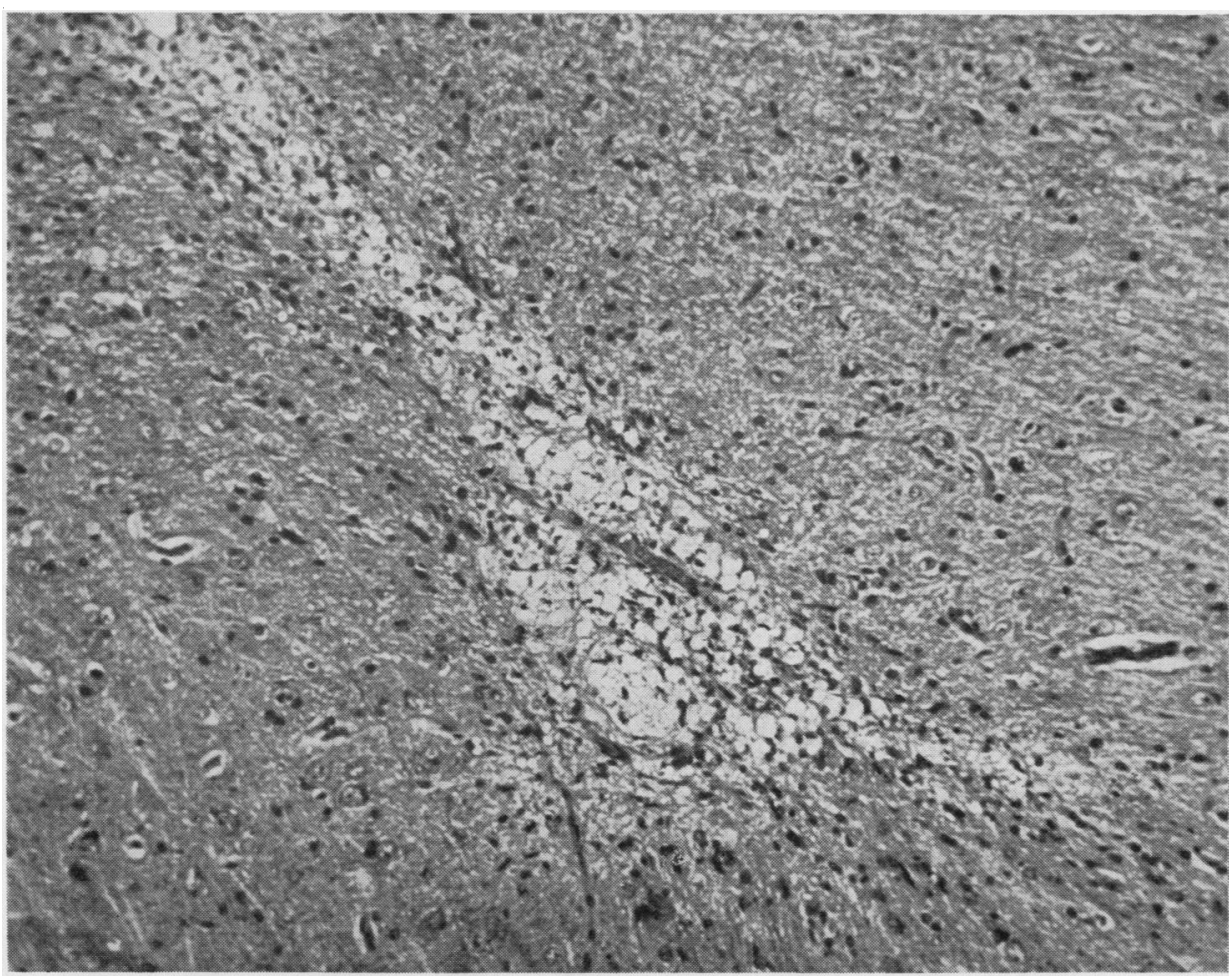

Fig. 7.-Cerebral infarct at junction of cortex and white matter. Dog. No. $6 . \quad \times 135$. 


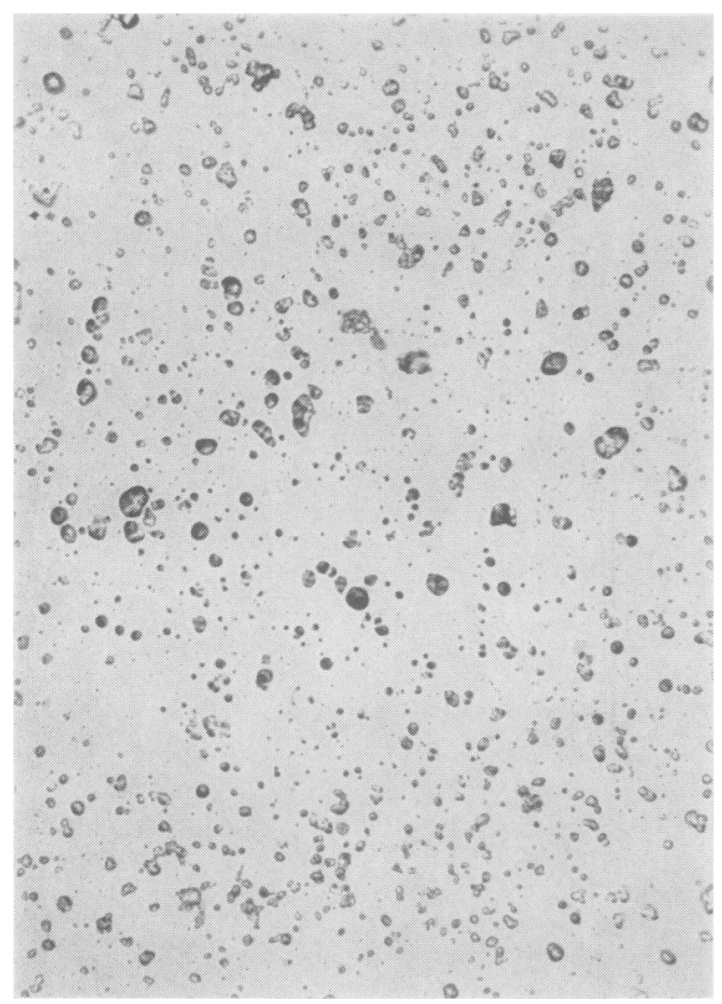

FIG. 8.-Globules of antifoam on a glass surface which had been dipped in a $20 \%$ solution of antifoam in ether and the ether allowed to evaporate. $\times 55$.

The only other pathological feature of note in other organs was a fairly marked phagocytosis of red cells and the production of haemosiderosis in the spleens of several of the dogs killed at three weeks.

Various methods of application of antifoam have been tried to eliminate the formation of emboli. None of these has been successful. Antifoam when applied to a surface either as an ethereal solution or spray forms globules as the solvent evaporates (Fig. 8). These globules are the order of $40 \mu$ with occasional larger ones of $100 \mu$. Diluting the solution results in fewer of the larger globules forming, but the small globules remain constant in size. Applying heat by autoclaving either to nylon or polyvinyl tubing to which antifoam has been applied does not cause it to adhere to the surface. The minimum number of emboli occurred in those dogs in which the minimum amount of antifoam was used.

\section{Discussion}

Several workers using equipment similar to ours have reported damage in the brains of experimental animals. Although the lesions have been of a focal type which suggests an embolic $\stackrel{\bar{S}}{\stackrel{乛}{9}}$ origin, the emboli were not demonstrated 0 (Giannelli and others, 1957 ; Taylor and Cavanagh, 흘 1958). Indirect evidence suggesting that antifoam $\frac{\bar{\sigma}}{\nabla}$ material might be responsible was provided by the $\stackrel{\mathbb{\Omega}}{\varrho}$ experiments of Giannelli and his collaborators, who demonstrated that only when antifoam was $\rightarrow$ used did cerebral damage result.

A probable explanation for the failure of others $\overrightarrow{\vec{\omega}}$ to discover antifoam emboli lies in the solubility $\mathcal{O}^{\circ}$ of the material. It will be readily removed by $\vec{x}$ the ether solvents used in preparing tissues for celloidin embedding or by chloroform which is often used before paraffin blocking. Moreover, $\overrightarrow{\tilde{N}}$ the material is not stained by the usual histological ${ }^{N}$ techniques and may remain invisible except when $\stackrel{\circ}{5}$ phase-contrast microscopy is used.

Recently two papers have appeared demonstrating cerebral lesions due to antifoam. Penry. Cordell, Johnston, and Netsky (1959) produced $\vec{P}$ infarcts in the brains of dogs by injecting antifoam $\mathscr{\odot}$ into the carotid artery. Antifoam emboli were. demonstrated in the brain. Reed and Kittle (1959) also injected antifoam into the carotid of the dog and produced embolic lesions.

Apart from the embolic effects of antifoam it is not toxic. We have observed no tissue reaction to $\stackrel{\square}{\mathbb{D}}$ the material, which, since it is insoluble in water, $\overrightarrow{\vec{P}}$ is inert. Nevertheless it does contain free colloidal $\frac{}{3}$ silica, which, though clearly in this form is less irritant than when crystalline, may have undesirable effects if it is to lie in the body indefinitely.

Although many emboli were found in vessels far from infarcts of the brain it cannot be assumed $\underset{x}{\tilde{x}}$ that such an obstruction of the blood flow has not damaged the brain. It is likely that ischaemia to a degree short of producing tissue destruction $\delta$ may interfere temporarily, at least, with function. 3 This is of particular importance in the vital centreso of the brain-stem, a factor perhaps contributing to the immediate mortality of the operation.

We have been impressed by the widespread destruction of nervous tissue that could be presenter in a dog, apparently normal after perfusion. N However, reduction of the amount of antifoam N used has produced certain striking changes in the ${ }_{\sigma}^{\omega}$ behaviour of our animals. First, it has increased the survival rate, and secondly the animals have $\frac{0}{0}$ recovered consciousness more rapidly. In our@ earlier experiments there was a marked depression 7 of cerebral activity when perfusion was started; this was originally believed to be due to the barbiturate used to anaesthetize the donor dogs. $\frac{\text { }}{\mathbb{D}}$ However, since decreasing the amount of antifoam $\frac{2}{-}$ the level of consciousness now lightens at the onset of perfusion. 
There are few reports of physiological studies of the effect of bubble oxygenators on cerebral or renal function. Owens, Adams, Dawson, Lance, Sawyers, and Scott (1958) made electroencephalographic observations during cardiopulmonary by-pass on 150 dogs and 23 patients using bubble and filming oxygenators. With both microbubble and macrobubble oxygenators undesirable alterations in electrical activity were observed in contrast to a filming oxygenator which produced little alteration from the base-line pattern. The effect of antifoam in a blood-brain barrier test (Hodges, Sellers, Story, Stanley, Torres, and Lillehei, 1958) showed that excess of the material produced breakdown of the blood-brain barrier. Many of the reports on neurological defect following extracorporeal circulation with bubble oxygenators have attributed the disorder to gas emboli (Maloney, Longmire, Schmutzer, Marable, Raschke, Watanabe, Lobpreis, and Arzouman, 1958). Our own experience of this aspect of the problem is limited, but at low flow rates we have not found gas emboli and it would seem that this factor has been overemphasized. More antifoam particles are found in the renal glomeruli than elsewhere and it would therefore be expected that the bubble oxygenator might cause suppression of renal function.

The way in which polymethylsiloxane antifoam acts as a defoamant is not understood, but it is an effective defoaming agent if sufficiently dispersed. There is probably no support for the concept that adherence alone to the debubbling surface is adequate for defoaming (Penry and others, 1959). It has been noted by many observers, including ourselves, that during the course of a perfusion the effectiveness of the defoamant gradually diminishes, and the presumption is that it passes into the circulation. This has been conclusively demonstrated by Reed and Kittle (1959). Since antifoam is not soluble in water it will act as particulate matter in the circulation and give rise to emboli.

Any extracorporeal system that requires antifoam will carry a risk of antifoam emboli. However, if this can be reduced to a minimum the apparatus may be used with great success (DeWall, Warden, and Lillehei, 1958). Antifoam is only effective when it passes into the blood, and attempts to fix it to the wall of the debubbling chamber are useless. It is clear that at any given flow rate the smaller the amount of antifoam used the fewer the emboli. To achieve this the first essential is to reduce the foaming of the blood to a minimum by using a low perfusion rate (in the region of $50 \mathrm{ml} . / \mathrm{kg}$. body weight) and the lowest effective oxygen flow rate (blood gas ratios $1: 4$ ). The antifoam should then be situated so as to keep it out of the main stream of blood in the debubbling chamber, but in contact with any foam that forms. This can best be achieved by applying the antifoam to a nylon mesh which is placed in the defoaming chamber. For flow rates of up to $1,000 \mathrm{ml}$. per minute $0.44 \mathrm{~g}$. of antifoam is adequate for a 30-minute perfusion. Reed and Kittle (1959) have arrived at a similar figure and shown that the amount of antifoam required will be approximately doubled if the perfusion is required to continue for over 90 minutes. It may be pointed out that the particles of antifoam will not be removed by the standard mesh filter.

The evidence which we have presented suggests that this type of apparatus carries an inherent risk of cerebral damage from antifoam emboli.

\section{SUMMARY}

Experimental work on dogs using a bubble oxygenator has shown that the system inevitably produces emboli. These are due to the defoamant polymethylsiloxane. In a high proportion of animals cerebral infarcts result from these emboli. Some animals had extensive infarction of the brain without demonstrating any functional neurological disorder. The bubble oxygenator carries an inherent risk of cerebral emboli from antifoam.

The authors wish to acknowledge the generous financial assistance they received from the Board of Governors, United Manchester Hospitals, and assistance in the preparation of the figures from the Department of Medical Illustration, Manchester Royal Infirmary.

\section{REFERENCES}

Clark, L. C., Gollan, F., and Gupta, V. B. (1950). Science, 111, 85 Cooley, D. A., Belmonte, B. A.. De Bakey, M. E., and Latson, J. R. (1957). Ann. Surg., 145, 898.

DeWall, R. A., Warden, H. E., and Lillehei, C. W. (1958). In Extracorporeal Circulation, ed. J. G. Allen, p. 41. Thomas, Springfield, Illinois.

Springfield, Illinois. Obstet., $104,699$.

Giannelli, S., Molthan, M. F., Best, R. J., Dull, J. A., and Kirby C. K. (1957). J. thorac. Surg., 34, 563.

Hodges, P. C., Sellers, R. D., Story, J. L., Stanley, P. H., Torres, F., and Lillehei, C. W. (1958). In Extracorporeal Circulation, ed. J. G. Allen, p. 279. Thomas, Springfield, Illinois.

Lillehei, C. W., Warden, H. E., DeWall, R. A., Stanley, P., and Varco, R. L. (1957). A.M.A.Arch. Surg., 75, 928.

Maloney, J. V., Longmire, W. P., Schmutzer, K. J., Marable, S. A. Raschke, E., Watanabe, Y., Lobpreis, E. L., and Arzouman, J. E. (1958). Surg. Gynec. Obstet., 107, 577.

Owens, G., Adams, J. E., Dawson, R. E., Lance, E. M., Sawyers J. L., and Scott, H. W. (1958). Surgery, 44, 240.

Penry, J. K., Cordell, A. R., Johnston, F. R., and Netsky, M. G. (1959). 'J. thorac. Surg., 37, 342.

Reed, W. A., and Kittle, C. F. (1959). A.M.A. Arch. Surg., 78, 220.

Reed, W. A., and Kittle, C. F. (1959). A.M.A. Arch. Surg., 78, 220. 280 .

Taylor, D. G., and Cavanagh, J. B. (1958). Guy's Hosp. Rep., 107,

Yates, P. O., Cassie, A. B., Dark, J. F., Jack, G. D., and Riddell, A. G. (1959). Lancet. 1, 130. 